\title{
La ética del investigador frente a la producción y difusión del conocimiento científico
}

\author{
Márquez-Fernández, Álvaro*
}

\section{Resumen}

En esta ponencia se parte de una definición general de la ética, para después considerar la importancia del cumplimiento de las normas éticas como un bien para la vida ciudadana. De este modo, la reflexión sobre la ética termina asociada con la responsabilidad moral de nuestras acciones cívicas. Eso nos sirve de base para justificar un razonamiento que permita emitir juicios validos sobre las prácticas valorativas, buenas o malas, tanto de los ciudadanos como de los miembros de una comunidad científica. En ese contexto es que debe situarse nuestro interés por la práctica o "ética aplicada" del investigador, sobretodo cuando se violentan o lesionan los derechos de autor de alguien que ha producido una obra o conocimiento original e inédito.

Palabras clave: Ética del investigador, conocimiento científico.

Recibido: 01-06-11 . Aceptado: 01-11-11

Profesor de la Universidad del Zulia. Director de la Revista Utopía y Praxis Latinoamericana.

E-mail: amarquez@luz.ve

1 La versión original de este trabajo se presentó como ponencia central en las Jornadas de discusión sobre la gestión de las revistas científicas arbitradas, realizadas en la Facultad de Ciencias Económicas y Sociales de la Universidad del Zulia, del 29 de mayo al 1ํ de junio de 2001. Está recogida en las Memorias bajo el título: "Ética del investigador y derechos de autor, su aplicación a la publicación de artículos arbitrados en revistas científicas". Para esta nueva publicación, se han creado algunas secciones y complementado otras, con el propósito de hacer más preciso el desarrollo del tema analizado. 


\section{The Ethic of the Researcher in the Production and Diffusion of Scientific Knowledge}

\section{Abstract}

This paper begins with a general definition of ethics, and proceeds to consider the importance of fulfilling ethical norms for the good of civic life. In this manner, a reflection on ethics ends up associated with moral responsibility in our civic actions. This serves as a basis for justifying thoughts that permit us to offer valid judgments on valorous actions, good or bad, both on the part of common citizens and by members of a scientific community. In this context, we concentrate our interest on the practice, or applied ethics, of the researcher, especially when someone's authorship rights in the production of an original or unpublished work are violated or damaged.

Key words: Researcher ethics, scientific knowledge.

\section{Introducción}

La preocupación por una conducta personal y colectiva, orientada por principios que hagan viable una vida feliz y buena, siempre ha sido uno de los ideales de toda sociedad organizada políticamente. El orden político de cualquier sociedad se basa en el desarrollo de relaciones sociales que permitan modelos de comportamientos que, sin negar la beligerancia, puedan ser aplicados, y a la vez cumplidos, por la mayoría ciudadana, a fin de lograr óptimos grados de solidaridad. Sin embargo, podría decirse que el orden político en sí mismo es insuficiente para garantizar la convivencia de quienes forman parte de la sociedad, se requiere de otros valores universales para que la legitimidad política sea reconocida por todos, más allá de los intereses particulares.

Entre esos valores podríamos señalar los éticos y los morales. Éstos permiten que los individuos de una sociedad decidan y acepten la mejor manera de lograr sus fines. De allí que tanto la política como la ética son dos esferas de la vida social que no deberían estar separadas (Pía Lara, 1992). Si en la esfera de la política es donde se produce el reconocimiento del poder y el encuentro con el otro, es en la esfera ética y moral donde ese reconocimiento alcanza, por parte de los individuos, el debido escenario para que la participación y el consenso se den en mejores condiciones de igualdad y respeto.

Esto ya nos habla, desde la antigüedad clásica (Jaeger, 1968), del valor de la ética como principio de regulación ciudadana para la participación política, es decir, actuar de acuerdo a valores y de esta manera crear las intersubjetividades necesarias que nos permitan acuerdos y compromisos a favor del bien en común.

La ética es una mediación que debe orientar cualquier acción práctica en el mundo de la política y en el mundo social. Por esta razón la presencia de la esfera ética en la convivencia humana nos permite la elaboración de juicios de valor que sirven de referencia para el diagnóstico de 
las conductas, y así poder considerar el beneficio o perjuicio de éstas.

Desde este punto de vista, nos interesa presentar el tema que vamos a analizar. Todos sabemos de la importancia de la ética para la vida ciudadana, más todavía para aquellas prácticas en las que nuestras acciones nos enfrentan a tomar decisiones en las que los valores éticos y nuestra conciencia moral, se ven comprometidos con la verdad y la honestidad de ciertas conductas, cuyos fines no siempre están determinados por el bien en común o los intereses compartidos. Eso, evidentemente, termina por afectar no sólo el orden político general, sino la actividad ciudadana particular.

Entrando en el tema que nos ocupa, en la sociedad actual se reclama, cada vez más, la responsabilidad y el compromiso ético de los ciudadanos en sus actividades. De manera creciente la esfera de la ética se ha venido ampliando y extendido a los más diversos sectores. No puede sorprender, entonces, que en una de las principales actividades que se cumplen en la sociedad, como es la investigación científica y humanística universitaria, la pregunta por la condición ética del investigador, en los resultados de sus investigaciones, también sea válida.

Esta pregunta no supone en modo alguno, una duda a priori sobre los principios éticos que rigen la vida del investigador, sino que plantea de manera directa la conducta del investigador con respecto a las normas éticas de la comunidad científica a la que él pertenece. En una sociedad tan consumista y competitiva como la actual, tanto los sujetos como los procesos de investigación -y sus respectivos medios de difusión- no escapan a una mercantilización del conocimiento, que en más de una oportunidad está en clara oposición con los valores éticos que deben estar representados en toda producción científica de conocimientos.

Es amplio el espectro de este problema. Puede verse desde varios puntos de vista, aquí solo mencionaremos dos. Uno, el que se refiere a la responsabilidad ética del investigador en la producción del conocimiento; otro, el que tiene que ver con la intención del fraude, el plagio, etc., animan a un sujeto o grupo a usufructuar los resultados científicos de otros investigadores en su provecho. Desde este punto de vista desarrollaremos el tema propuesto; en particular, lo que atañe a la ética del investigador en la producción y difusión del conocimiento a través de las revistas arbitradas de universidades nacionales e internacionales, haciendo énfasis, al final, en la relación entre ética y algunos de los problemas más comunes que se presentan a los derechos de autor.

\section{La ética como norma universal de vida}

\subsection{Vigencia histórica de la Ética}

La preocupación por entender las acciones a partir de principios éticos, está presente en los principales pensadores de la filosofía. Los individuos deben estar dotados de normas morales, básicas y fundamentales, deberes universales que les permitan un desenvolvimiento social óptimo y justo.

Aristóteles representa la culminación de todo un pensamiento, en el que la ética debe determinar el fin de nuestros intereses. Eso es lo que haría al hombre vir- 
tuoso, sabio, alcanzando el verdadero placer que le es dado al hombre feliz (Aristóteles, 1985: X,4,1174b). Se trata de que el hombre viva moralmente a fin de que escoja la práctica de la justicia. En la justicia el hombre logra la principal virtud ética (Aristóteles, 1985: V) y en ella se funda el derecho, la sociedad y la ciudadanía.

Pero la ética clásica ha ido ampliando su significado, a través de diversas influencias, la del kantismo entre ellas. Es Kant otro de los grandes pensadores que centra su reflexión en el tema ético, y le da el carácter de "imperativos" a los principios éticos, de esta manera Kant considerará que la ley moral no es ajena a la misma personalidad que la ejecuta (Kant, 1963). La ética queda comprometida con el 'deber' y no tan sólo con el 'bien'. El cumplimiento de la obligatoriedad del deber, sólo es posible si nuestra conciencia moral está dispuesta a reconocer la importancia de vivir la vida desde una experiencia de valor como absoluta, universal. El deber moral no responde a compromisos ni a intereses personales, en eso se distingue de otros deberes o leyes que no nacen de la autoridad sino del poder o la sanción.

La ética puede entenderse desde diversos puntos de vistas: deontológica, contractualista, utilitaria, pragmática, y más recientemente discursiva y comunicativa. Estas diversas posturas sobre la ética mantienen un común denominador: un esfuerzo teórico y práctico por analizar el componente de moralidad de las relaciones humanas, y cuándo éstas están estructuradas por ciertos valores aceptados para alcanzar un propósito en común (Cortina, 1996a). Cualquier proyecto éti- co de vida, individual o social, va a representar un compromiso en el que la búsqueda por valores transcendentales compartidos, estará condicionando la felicidad y la paz, la libertad y la tolerancia, la prudencia y la necesidad, entre los seres humanos y sus diversas manifestaciones culturales.

Le toca al hombre moderno, hoy más que antes, retomar el compromiso ético de sus acciones, hacerse responsable de sus resultados, ya que siendo los deberes razonables, no son deducidos 0 derivados simplemente de los hechos, es importante conocer su carga argumentativa, es decir, buscar las explicaciones sobre el por qué de las acciones cumplidas, sus pro y contra. Los valores que niegan los principios éticos, para todas las épocas y circunstancias, son valores que están en franca oposición con la práctica de la verdad, la solidaridad, la lealtad, la fidelidad, la justicia. El núcleo duro de la ética es producir estructuras normativas (Cortina, 1986) que estén y sirvan de garantía para un mejor comportamiento público de la ciudadanía y las principales instituciones que la representan. Una sociedad regulada éticamente, supone un orden de moralidad pública en el que la mayoría de los individuos pueden realizarse en sus libertades básicas.

Por otra parte, señala $C$. Thiebaut (1992: 48) que "la recuperación de la idea aristotélica de virtud está vinculada a la reivindicación de una idea sustantiva de bien como objetivo de la ética -que debe responder a la pregunta de qué modo la vida es deseable-, la de una comunidad moral que define el lugar de lo ético, y la de un juicio-valoración moral que se realiza de forma contextual y específica". La 
idea de virtud está vinculada a la posibilidad de construir el mundo material la comunidad moral, donde los miembros de ella estarían en capacidad de poner en práctica el ideal estoico de la dignidad moral y la idea de felicidad como bienestar, a fin de evitar los conflictos de cualquier clase.

El reclamo de una actuación ética en todas y cada una de las acciones humanas, pone de relieve la importancia de valorar, como diría Kant (1963), la dignidad intrínseca de la persona moral, lo que supone de antemano la posibilidad de una convivencia humana abierta a la libertad, donde la aceptación de las normas equivale a cumplirlas en beneficio de todos.

\subsection{La ética como campo normativo}

Toda comunidad o sociedad humana, más allá de sus diferencias, se rige por normas y valores. Éstos no tienen por que ser complejas construcciones racionales de intrincados conceptos. Basta con que se guarde una correspondencia, por mínima que sea, entre las normas que deben ser cumplidas y aquellos valores que se prescriben como validos para todos. Por esto, cuando se habla éticamente de la Justicia, la Verdad, la Democracia, etc., estamos hablando de términos cuya significación queda representada por la universal noción de valor que un colectivo particular le ha atribuido, con la expresa intención de que sean reconocidos como tales.

Estos valores se harán prácticos si nuestras acciones, y comportamiento cívico, se encuentran orientadas normati- vamente por la voluntad axiológica que se requiere para darles cumplimiento. Lo contrario supone negar y/o poner en duda la validez de las normas que se desean presentar como paradigmáticas de una forma de comportamiento animada por una convivencia que persigue el bien en común (Gomez-Muller; 1999).

En teoría esto pudiera ser una argumentación que quizás satisfaga a la mayoría. Pero en la práctica no siempre la coexistencia obligada entre validez y valor de una norma es aceptada o reconocida por todos. Ninguna mayoría es homogénea y absoluta. Es más, toda mayoría tiene, al parecer, dialécticamente, una minoría que se le opone o contradice (siendo esto una de las principales reglas de la democracia moderna). De allí, y para bien de cualquier teoría, todo juicio de valor es siempre relativo, inacabado, y en consecuencia perfectible.

Compartimos la definición que nos ofrece A. Cortina (1998: 20-21) de la ética, al considerarla como "un tipo de saber práctico, preocupado por averiguar cuál debe ser el fin de nuestra acción, para que podamos decidir qué hábitos hemos de asumir, cómo ordenar las metas intermedias, cuáles son los valores por los que hemos de orientarnos, qué modo de ser o carácter hemos de incorporar, con objeto de obrar con prudencia, es decir, tomar decisiones acertadas." Es obvio advertir que la ética se nutre cada vez más de la contextualidad social y política en que vivimos. Lo que hace suponer que detrás de cada acto humano, por simple que lo consideremos, existe un plano éti$\mathrm{co}$, es decir, responsabilidades y obligaciones para con uno mismo y los demás. 
Aun cuando la mayoría de un colectivo, cualquiera que sea, p. ej., comunidades religiosas, familiares, de hermandad o fraternidad, educativas, científicas, empresariales, etc., acepte la validez de un sistema normativo por el que orientarse éticamente, no siempre esto supone el acato por parte de todos a los medios por los cuales se hace realizable aquello que se supone favorece el modo de convivencia que se ha estimado como válido. Precisamente, puede observarse que casi siempre al margen de estas normas, subsisten individuos o grupos que aun cuando aceptan su valor, al no acatarlas reducen o restringen el campo de su validez práctica, desentendiéndose de la forma cómo los valores deben ser cumplidos como propios, a la vez que compartidos.

Entonces, cuando se habla éticamente de Justicia, Verdad y Democracia, repetimos, nos estamos refiriendo a la ejecución de valores establecidos que son y deben ser compartidos por la mayoría. Los fines de esos valores deben procurarnos ciertos principios de autenticidad y fidelidad que nos permitan una mejor convivencia y credibilidad. El valor de estos valores dependerá de su puesta en práctica, o sea, del momento de su construcción real, de su encarnación en la realidad, y ello dependerá de la honestidad con la que se cumplan, en claro enfrentamiento con la falsedad. Como decía Aristóteles (1985, V, 3, 1130 a,9), la vida práctica sólo es virtuosa si nos comportamos como seres humanos justos, es de$c i r$, seres racionales que tienen como norma común, valor compartido, la prudencia (phrónesis). Norma de vida que contribuye a realzar la existencia y a proyectarla a su más alto nivel de felicidad.

\subsection{La ética social como tejido axiológico de los grupos humanos}

No se puede renunciar a la ética y a sus principios en una sociedad cuyos valores humanos están cada vez más devaluados. Anti-valores que han pervertido los medios con tal de lograr unos intereses particulares cuyos fines se oponen a los generales, ésos que la mayoría ciudadana desea para su realización (GomezMuller; 1999). Esto justifica desde todos los aspectos la reflexión ética en los diversos ámbitos de la vida social, y en consecuencia la posibilidad de ejercer un juicio crítico sobre las prácticas valorativas del hombre moderno.

Tenemos entonces, que por medio de la ética podemos valorar y evaluar el campo público y privado de la moral, y dar opinión de aquellos comportamientos y actitudes que se corresponden o no con los principios éticos que enmarcan cualquier acto individual o colectivo. A saber, todos aquellos principios que deben contribuir al bien, a la prudencia y a la justicia (Aristóteles, 1995, VI, 9, 10 y 11).

Desde la ética y la moral también se dan respuestas y se hacen críticas a los actos que le son contrarios. Aunque no existe una ética de sanciones, la ética establece responsabilidades sobre los actos cometidos. Ella no es un código de castigos y penas, en el sentido jurídico. La ética, al razonar sobre conductas valorativas, puede cumplir funciones de crítica deontológica al preguntarse sobre la responsabilidad moral, positiva o negativa, de alguien que se reconoce como autor de sus actos, ante su propia conciencia y la sociedad. 
Aplicar a alguien el principio de "moralmente responsable", según sea el acto cometido o realizado, implica que equis persona es responsable de lo que ha hecho porque precisamente hubiera podido actuar de forma distinta a como lo ha hecho; sobre todo, cuando el hecho cometido ha producido un perjuicio contra otra persona (o personas). En tal sentido la ética se vincula con la libertad y nuestra prudencia para saber elegir. "Si tengo conciencia de que puedo obrar en un sentido determinado, es porque puedo elegir ese camino u otro" (Cortina, 1998: 21).

La ética normativa se ocupa de la justificación de las normas, criterios y valores morales así como de la fundamentación de esos juicios, y cuándo, dónde y por qué los actos humanos al dejar de ser buenos, solidarios, etc., deslegitiman las normas y las corrompen, haciendo muy problemático el campo de la verdad y el reconocimiento con los otros. Esto es así, porque el mundo se asume como una experiencia de valor: "la experiencia normativa, cualquiera ella sea, es valoración, porque la conciencia de la vinculación de la conducta es el producto de la libertad como deber hacer. La norma aparece, entonces, como racionalización o justificación objetiva del acento establecido por el acto valorativo (...) la norma y el juicio de valor son dos momentos de un mismo proceso espiritual o, para ser más exactos, que la norma es la versión exigible o incitativa de la valoración práctica" (Delgado Ocando, 2000: 26). Al hablar de valoración práctica, nos estamos refiriendo al contexto de acción donde la norma se establece y se cumple, donde la valoración está sujeta las consideración de las opiniones de los otros, pues se trata de discernir el tipo de intervención que producimos en el mundo. La justificación o no de una norma de valor, dependerá, entonces, de la relación de nuestras conductas sociales con los fines trazados, bien para juzgar nuestra conducta como para evaluar el comportamiento ajeno. EI compromiso vital que nos liga a esta exigencia es la medida de nuestra autenticidad (Delgado Ocando, 2000: 28).

Tenemos entonces que la ética versa sobre una forma o manera de actuar; prescribe y describe aquellos valores que hacen posible ese modo de actuar acorde con el sentido de prudencia, justicia y felicidad de las conductas que nos sirven para relacionarnos. Lo contrario nos pone a la deriva desde el punto de vista de los valores.

Una comunidad o sociedad sin orden ético, es una sociedad desmoraliza$\mathrm{da}$, donde las relaciones humanas terminan mediadas por un tipo de interés utilitarista y pragmático, que no está asociado en modo alguno con el servicio de un bien común compartido y participativo. El actuar ético supone hacer lo que es moralmente bueno para uno y los demás. Actuar de modo contrario, ha supuesto, como lo ha demostrado la experiencia histórica, una pérdida de la conciencia moral de la sociedad, como el principal referente en la construcción de decisiones racionalmente justas.

\section{4. Ética individual, ética cívica y ética aplicada}

La Ética no solamente se interesa por el respeto y cumplimiento de los de- 
beres, sino también por el de los derechos. No puede haber colisión entre deberes y derechos, éticamente normados. Cuando la prescripción ética alcanza y reviste valorativamente la acción normada por el derecho, éste se convierte en un sucedáneo de aquellos bienes que la ética toma como fines a realizar. Siendo así, la conciencia moral de una sociedad puede recusar, entonces, aquellas actuaciones individuales o institucionales que resulten de una práctica deshonesta en el cumplimiento tanto de los deberes como de los derechos.

Adela Cortina nos habla de una ética aplicada y de una ética cívica. La ética aplicada la entiende como la aplicación de "los resultados obtenidos en la parte de fundamentación a los distintos ámbitos de la vida social: a la política, a la economía, la empresa, la medicina, la ecología, etc. Porque si al fundamentar hemos descubiertos unos principios éticos, la tarea siguiente consistirá en averiguar cómo pueden orientar esos principios los distintos tipos de actividad" (Cortina, 1998: 32).

La ética cívica, que nace del pluralismo, es una ética de mínimos morales compartidos (a través de los valores de libertad, igualdad y solidaridad) por los ciudadanos: "consiste en ese mínimo de valores y normas que los miembros de una sociedad moderna comparten, sean cuales fueren sus cosmovisiones (...); mínimos que les lleva a comprender que la convivencia de concepciones diversas es fecunda y que cada quien tiene perfecto derecho a intentar llevar a cabo sus proyectos de felicidad, siempre que no imposibilite a los demás llevarlos también a cabo" (Cortina, 1998: 37).
Gracias a la ética cívica, dice Cortina (1998), es que podemos pensar la existencia de una pluralidad de morales, distinguiendo una gran diversidad de espacios éticos desde los cuales asumen sus identificaciones aquellas organizaciones sociales que buscan establecer lazos de convivencia. Debido a este pluralismo moral que se desarrolla en la Modernidad es que, para Cortina (1998), hoy se puede hablar de una ética empresarial, una ética médica, una ética ecológica, y lo que es nuestro tema de estudio: una ética del investigador (habida cuenta de que también puede hablarse de una ética de la investigación).

El planteamiento que propone esta destacada filósofa española sobre su visión de la ética aplicada y cívica, nos permite afirmar que vivimos en una sociedad de valores y que dependerá de nuestras conductas morales y éticas la legitimidad de éstos. Cada vez más el imperativo categórico versa sobre las condiciones fácticas de una ética aplicada y cívica capaz de "remoralizar la sociedad"; es el nuevo norte de la ética de las organizaciones o de las instituciones, como señala Cortina. Es decir, su preocupación se centra en establecer los parámetros dentro de los cuales la ética plantee claramente sus definiciones con respecto al fin específico, el bien interno, los medios, los hábitos y el carácter. Sólo así es que las organizaciones pueden llegar a cumplir con su cometido ético y moral entre sus principales beneficiarios, los seres humanos en general, los ciudadanos de una sociedad en particular.

Cuando somos capaces de reconocer la correspondencia fáctica entre los principios de fundamentación ética y el 
cumplimiento de éstos en la acción práctica (política, empresarial, investigativa, etc.), es cuando llegamos a saber que la conexión entre principios y acciones resulta de las relaciones que los individuos generan entre sí, dotando el ámbito de lo ético de características particulares y específicas. Indagar en el contenido de estas características y sus respectivos condicionamientos, para el logro de las finalidades, metas, etc., es lo que está en el fondo de la tesis de Cortina, más aún cuando señala como caso particular, que "la ética de la empresa -(al igual que cualquier otra p. ej. la docente, la sanitaria, etc)- es, en este sentido, una parte de la ética aplicada" (Cortina, 1998: 33). Entonces interesa saber cuáles son los propósitos de la empresa en relación con el logro de sus fines, sobre todo cuando es vox populis que la ética aplicada de la empresa capitalista, está orientada por la maximización del beneficio en su favor y no del beneficio colectivo.

No es el caso de seguir aquí un análisis pormenorizado el pensamiento de Cortina (1988), con el que coincidimos y disentimos en diversos momentos y conceptos. Nuestro propósito en este aparte es solamente remarcar, muy contrariamente a cualquier postura metafísica e idealista, que la ética es una ética -parafraseando a Sartre- de situación. Y es por eso que es humana y en cuanto tal siempre responde a las normas y valores -aún trascendentales- que los seres humanos le adjudican. El desarrollo ético del género humano, dependerá, en consecuencia, del progreso de su moral cívica para aceptar o disentir normas y valores, como se deja ver en este trabajo.

\section{La Ética del investigador frente a la producción del conocimiento científico}

\subsection{La ética del investigador}

Bien se sabe que el conocimiento no es neutro. La investigación científica de la que surge tampoco lo es. Menos aún, el sujeto o los sujetos que le dan origen a tal actividad y proceso. Aquella tesis de la neutralidad valorativa, ha quedado en el pasado por su función ideológica interesada. La presunción de que el conocimiento pueda ser algo totalmente objetivo, donde la influencia del sujeto en el objeto es nulo, precaria, o inexistente, está completamente superada. La actuación humana es la que impregna de sentido la construcción racional de la realidad. Sin esta acción sería casi imposible una valoración ética sobre los fines de las acciones y su comportamiento intencional (Delgado Ocando, 2000).

Efectivamente toda investigación es una especie de vector sobre la realidad: origen y retorno sobre ella y el sujeto. Esta correlación permite considerar a la investigación científica en un sentido pragmático, como parte de la vida y en cuanto tal, como algo que puede influir y determinar normas y conductas de los investigadores.

Debemos concebir la investigación como un proceso dirigido a la producción del conocimiento y su difusión, pero en el marco de un compromiso ético que garantice la credibilidad de ese conocimiento y su aplicación humanitaria. El investigador es uno de los principales responsable de la producción del conocimiento 
ante la sociedad, de manera que él mismo debe darle un sentido ético a la finalidad y los objetivos de la ciencia. La ética del investigador no puede ser, socialmente hablando, independiente de la verdad y la utilidad del conocimiento. La investigación y sus resultados, quedan envueltos por la cultura y los valores del investigador. La conducta del investigador forma parte de un sistema de valores compartidos. De alguna manera su personalidad queda representada en su voluntad ética, y ella termina siendo reconocida por la comunidad científica y la misma sociedad como equivalente de lo justo, equitativo y honesto de su compromiso con la verdad. El conocimiento verdadero será el propósito central del investigador, debe lograrlo a partir de una correcta concreción entre su conducta personal y su ideología investigativa, que no debe tergiversar y falsear el conocimiento final de su trabajo, menos pasar como original resultados de otros colegas investigadores.

\subsection{Incumplimientos éticos del investigador y sus repercusiones}

La importancia de la reflexión de Cortina (1998), con respecto a la ética aplicada y cívica, tan sucintamente expuesta, nos da la oportunidad de reflexionar sobre algunos de los problemas propios de la "ética del investigador" cuando ésta no es cumplida cabalmente, y su consecuente conflicto desde el punto de vista de los "derechos de autor", cuando son éstos lo que terminan siendo afectados por una expresa falta de ética.

Las faltas éticas son faltas que se comenten en el ámbito de la moralidad pública, cívica. En ese sentido estás fal- tas pueden ser objeto de discusión y crítica por parte de un individuo, comunidad o sociedad que se sientan afectadas por ellas. Se incumple lo que debe ser y en este incumplimiento se transgreden ciertos valores que han sido normados universalmente, con la finalidad de garantizar el bien, la justicia, la verdad, la honestidad, la fidelidad, la solidaridad -entre otros valores-, a quienes los ejercen de común acuerdo.

Existe de manera implícita y explícita un derecho a deber ser, que un individuo o colectivo asumen como código de conducta que honra y ennoblece. La convivencia de la comunidad o de la sociedad queda garantizada porque la finalidad de uno es la de los otros y viceversa. De este modo el valor de solidaridad con el que se comparte un valor-ideal no debe ser quebrantado por el interés egoísta de alguien. Eso supondría desaprobar tal conducta por ser contraria a los fines de todos.

\subsection{Una ética aplicada al campo de la investigación}

Cuando se habla de la ética del investigador, que debemos entender, según lo explica Cortina (1998), como una ética aplicada, estamos hablando de unos principios de legitimación, representación e identificación de una forma particular y original de actuar, producir y difundir el conocimiento científico y humanístico, en el ámbito de una comunidad intelectual que se confiesa respetuosa de la libertad creadora del otro, de su originalidad y autenticidad reflexiva y discursiva.

Queremos decir que estamos en presencia de un individuo o colectivo hu- 
mano que se ha preparado y formado dentro de los más exigentes requisitos metodológicos y epistemológicos de su área de especialización, dentro de sus respectivas normas y valores éticos. Sea por ejemplo, los del médico para quien el logro de la salud del enfermo es el bien final, o los del abogado para quien ese bien final está en la práctica de la justicia. De ninguna manera podría considerarse el usufructo de la profesión como medio para alcanzar ese fin.

Pero esta disposición a cumplir con las normas o los valores éticos, no es una disposición natural y espontánea del investigador, sino que resulta de una compleja trama de relaciones sociales que termina por definir un perfil, una actitud, un modo de ser, de razonar los problemas y tomar las decisiones de acuerdo a valores. Entonces, todo desempeño social incluye el desempeño de la profesión en relación con el entorno de esos valores que se han adquirido y que están implícitos en el cumplimiento moral y ético de la disciplina en la que se desarrolla el conocimiento. Un estadio no excluye al otro, ambos son coexistenciales. La línea divisoria entre el conocimiento científico y la ética, es completamente imaginaria. No se puede prescindir de la ética en la construcción del conocimiento, lo contrario supone, como sabemos, una mutación en el orden del saber que acentuaría, todavía más, la tendencia desmoralizadora del conocimiento humano por parte de la razón técnica, y que está tan bien caracterizada por Habermas (1973) en sus estudios sobre la sociedad capitalista avanzada.

Pues bien, la ética del investigador debe estar soportada por una volun- tad de actuar siempre con la verdad y la honestidad, en plena correspondencia con la comunidad científica a la que pertenece y a su contexto social. Una ética en la que el respeto a la autonomía de los interlocutores debe partir del respeto a sí mismo, así como de la confianza y tolerancia de la que debemos valernos para conciliar los diversos puntos de vistas y evitar las predisposiciones alevosas y personalistas.

Considera Cortina (1998) que la ética aplicada debe basarse cada vez más en la estructura dialógica de la racionalidad, a fin de abrirse de un modo más pleno a la deliberación, ya que"no se puede decidir qué normas son morales si no es a través de un diálogo que se celebre entre todos los afectados por ellas y que llegue a la convicción por parte de todos de que las normas son correctas" (Cortina, 1998: 31). Esto hace posible que la valoración del contenido de la norma básica exprese efectivamente, no el interés particular, sino el interés generalizable de todos aquellos que se siente representados en la aplicación de la norma, a fin de evitar los conflictos.

\subsection{La pérdida del sentido ético en el campo de la investigación}

Nos desenvolvemos en una sociedad en la que la competitividad y la usura, el tráfico de influencias y la corrupción a todos los niveles, incluso los más inimaginables, están coordinados cada vez más por el fraude, la estafa, el robo, el hurto, el plagio, la publicidad engañosa, la violencia de todo género, etc., a cuya influencia tampoco escapan los miembros de las comunidades científicas y académicas, 
generadoras por excelencia de la cultura, las artes y el conocimiento.

Hoy en día los resultados de la investigación científica, se encuentran amenazados por la Babel de la inmoralidad. En más de una oportunidad se ha venido constatando en nuestras comunidades científicas, aunque todavía resulten ser excepciones, conductas deshonestas $y / o$ delictivas por parte de algunos investigadores, en relación con la producción y divulgación de conocimiento. Algo que es realmente lamentable, si se entiende que es en estos particulares y hasta elitescos lugares del saber, donde deberían estar atrincherados los profesionales del bien pensar y del bien actuar.

$Y$ este es uno de los puntos álgidos que merece nuestra atención en esta oportunidad. Es el caso cuando el investigador falta a su ética, como suele decirse. Cuando su conducta deshonesta, sea por interés individual, adhesión política, rencilla personal, mediocridad intelectual, desafía abiertamente el êthos propio de su actividad profesional, infligiendo un grave mal a la comunidad de investigadores en la que se encuentra.

Ejemplos de esta realidad pueden ir desde la paráfrasis de una simple idea que se toma de otro autor, escamoteamiento o manipulación de una referencia bibliográ fica, hasta el plagio parcial o total de un texto; desde hacer caso omiso a las normas de presentación de un artículo, por ejemplo, la que prohíbe presentar el mismo artículo simultáneamente a dos revistas, hasta la reposición de artículos que con simples retoques se encubre su fecha de vencimiento; desde el pago económico por la realización de trabajos de grado, hasta la coacción o intimidación personal a un miembro de jurado para que falle o consienta a favor de alguien, etc. Son muchos los casos y situaciones que pudieran mencionarse, lo que nos hace suponer que la ética de algunos investigadores está fuertemente resquebrajada en sus fines, hábitos, metas, valores, carácter, como lo señala Cortina (1998).

El perjuicio que esta actitud inmoral causa a la academia científica y humanística de una universidad, es suficiente para que se denuncie el agravio que se comete contra la comunidad de investigadores, y aplicar aquellas sanciones disciplinarias instituidas por los reglamentos y las leyes universitarias -a veces civiles- creadas para tal efecto, con el objeto de "remoralizar" nuestras instituciones en su nivel práctico; es decir, recuperar el sentido que portan los valores de la actividad que nos es propia -investigación y docencia. Es necesario reflexionar seriamente sobre la mejor manera de lograr el desarrollo de los bienes internos y externos que corresponden a esa actividad, e igualmente los medios adecuados para actuar en esa dirección (Cortina, 1998: 24).

El reconocimiento y aceptación del status ético de la investigación, como de la docencia, debe ser entendido como algo más que un código de normas que deben respetarse a priori por un individuo o grupo de individuos. Es algo más complejo. El status ético de la investigación depende de la ética de los investigadores; es decir, de su desenvolvimiento moral para tratar con transparencia los diversos asuntos que conciernen a la creación y difusión de los conocimientos. Igualmente, del perfil con el que se debe valorar la misión científica que la universidad desea proyectar en la sociedad. De alguna manera esta sim- 
biosis entre los investigadores, los procesos investigativos y la ética académica, termina por galvanizar la moralidad privada y pública del investigador, siendo capaz de comprometer sus actos y su voluntad en la realización de unos valores que determinan la orientación práctica del conocimiento en función del bien, la justicia, la felicidad y la prudencia.

\subsection{Por una regulación normativa de la difusión de la investigación}

Darle respuestas a las causas de la desmoralización del conocimiento que se sufre en las universidades, y que pueden llegar a reflejarse en el principal de los medios de difusión de esos conocimientos, como lo son las revistas arbitradas, nos obliga a crear baremos que nos permitan evaluar los resultados de las investigaciones que se van a publicar. No solamente a través de la figura del arbitro, sino a través de procedimientos de selección y opinión de asesores internacionales que permitan densificar los criterios de confiabilidad que deben privar a la hora de acreditar no sólo la publicación de un artículo, sino la defensa de un trabajo de Maestría o de Tesis Doctoral. La posibilidad de retomar las cartas de presentación, sería un aval muy estimable que pudiera evitar, en menor grado, que enfrentemos ilícitos como los antes mencionados. De la misma manera, disponer del Currículo Vitae detallado de los investigadores, a fin de lograr mayor información sobre su trayectoria investigativa, pudiéndose contactar, de ser necesario, en situaciones de falta de ética, a quienes hayan desempeñados funciones de tuto- ría o asesoría en la formación científica del investigador.

Si bien los Consejos de Redacción, junto con el Director y Editor de las revistas, son los responsables natos de todo lo que se publica, de cualquier anomalía, la que va de la "fe de errata" hasta el plagio consumado, debemos considerar que esta es una responsabilidad limitada como en toda empresa, y se dan y darán situaciones que son y serán insalvables humanamente hablando. Como ejemplo de lo que decimos valga recordar el caso de Alan Sokal (Imposturas intelectuales, Paidós, 1988), que logró la publicación de un artículo suyo: "Transgredir las fronteras: hacia una hermenéutica transformadora de la gravedad cuántica", en la prestigiosa revista Social Text en 1996, que resultó ser, confesado por él mismo, una parodia antipostmoderna, antirelativista y antideconstructiva que logró burlar la buena fe y competencia profesional de los árbitros.

Cortina (1996b: 291-192), sugiere, como un instrumento alterno capaz de garantizar y discernir sobre el cumplimiento de las normas ética mínimas, la creación de Comités de Ética, dada la importancia cada vez más de la ética no sólo como fundadora de lo moral, sino también como reguladora de la moral cívica. Al respeto dice Cortina que "... la creación y proliferación de comités de ética es uno de los rasgos expresivos de este florecimiento del que la moral cívica y la ética aplicada vienen haciendo gala desde hace un par de décadas. En cada uno de sus ámbitos -empresarial, financiero, político, informativo, sanitario,- nacen comités de éticos con tareas diver- 
sas, como pueden ser el "descubrimiento" de los principios éticos de una determinada profesión, la redacción de códigos éticos, la supervisión de las actuaciones de los profesionales cuando plantean algún problema moral, el asesoramiento en caso de duda, la formación ética de quienes trabajan en un campo determinado".

No podemos ignorar o ser indiferentes ante situaciones o hechos que han traspasado el límite de lo tolerable o lo consensuado moralmente. Que el plagio se considere como un delito, ha dado pie a que el derecho legisle sobre el asunto. El llamado "derecho de autor", es una fórmula que permite declarar con lugar este delito, si se llega a demostrar como tal. Es una forma de amparo, de resguardo, del que se vale un autor para defender la originalidad y la realidad inédita de su obra. Entendiendo que su obra es una propiedad como cualquier otra, sólo que en este caso el concepto positivo de propiedad se refiere, como bien lo dice el código, a la propiedad intelectual de quien es el sujeto creador de la obra con respecto a su naturaleza, características, formalidades, etc.

Por derechos de autor podemos entender aquellos derechos, universales para todos, que son inalienables y corresponden a un sujeto que con respecto a su obra, se le define como el autor. Se reconoce la filiación de una autoría entre ese sujeto y su obra, un estado de pertenencia que se logra con la obra (filosófica, literaria, artística, teatral, cinematográfica, etc.), según haya sido producida por la particular inventiva de un individuo o colectivo. Lo que hace que esa obra no debe ser repetida o reproducida por alguien más, a través de cualquier medio, sin la previa y expresa autorización de quien ha sido declarado como el autor original (Ley sobre el Derecho de Autor, 1993).

La leyenda, ya de uso internacional, que presentan en sus primeras páginas la mayoría de los libros, con ligeras variables terminológicas: "Ninguna parte de esta publicación, incluido diseño de la cubierta, puede ser reproducida, almacenada 0 transmitida en manera alguna, ni por ningún medio, ya sea eléctrico, químico, mecánico, óptico, de grabación o de fotocopia, sin permiso previo del editor", suscrita, por un copyright conjunto, entre la Editorial Biblioteca Nueva (Madrid, 1997) y los herederos del filósofo español José Luis López Aranguren, puntualiza el reconocimiento jurídico que le otorga la ley al autor -extensivo a sus herederos- de una obra (libro, etc.) frente al público (usuario) general. La función del copyright, las siglas del registro internacional del libro (ISSN) y el número del depósito legal, buscan minimizar el plagio o la comercialización ilegal de la que es objeto la obra original de un autor y aquellos derechos patrimoniales que le son violentados por quienes logran hacer rentable económica y/o académicamente estos delitos.

Sólo cuando el autor o institución, le concede expresamente la licencia a otro u otros, para intervenir sobre su obra (libro, pintura, etc.,) es que su patrimonio intelectual se hace parte de otro dominio. Y ello siempre corresponderá al interés que tenga tanto el autor como la institución por divulgar y compartir los resultados y beneficios de la obra. En casos como estos encontramos, entonces, esta otra leyenda, con sus respectivas variables: "Se autoriza la reproducción de los artículos contenidos en esta revista, 
siempre que se cite la fuente y se envíen -a la redacción- dos ejemplares de la reproducción". Es la que presenta la revista PASOS del Departamento Ecuménico de Investigaciones (DEI), de la ciudad de San José de Costa Rica. Pero en ningún momento esto significa que el autor, los autores, o la institución, están renunciando a sus derechos de autor; en absoluto, sólo están favoreciendo una mayor libertad de investigación para intervenir en el debate y la crítica de sus ideas.

Esta es una actitud que ha potenciado con mucha fuerza el intercambio de información y el acceso a fuentes documentales con el desarrollo de INTERNET. Es el caso, por sólo mencionar un ejemplo, del portal ciberespacial de la Comunidad Virtual de Filosofía que anima el Dr. Paulo Ghiraldelli Jr, de la UNESP en São Paulo, Brasil. A una de mis preguntas sobre los derechos de autor para la traducción de un texto de Richard Rorty al castellano, aparecido en el portal, me respondió que todos los documentos que allí se presentaban habían sido liberados por sus autores de cualquier permisología concerniente a derechos de autor; que cualquier participante de los foros, de la lista de discusiones, etc., del portal, tenía el derecho de acceder a la información y a transferirla. Lo que por otro lado, ha hecho proliferar, lamentablemente, la difusión de investigaciones y resultados científicos que son plagiados a nivel planetario. Esta es una realidad que ha llegado para quedarse y, al parecer, más aún en países en los que una tribu de investigadores, por no tener una tradición y una cultura de responsabilidades éticas en las investigaciones, son presa fácil de la tentación del plagio parcial o total, etc.
Resulta imposible fiscalizar en cualquier área de la investigación científica, por muy especializada que sea, desde los directorios hemerográficos hasta los ficheros bibliográficos, el incuantificable caudal de los originales aportes que científicos de todo el mundo producen diariamente. Lo que incrementa cada vez más las probabilidades del investigador deshonesto para fraguar su estafa, al valerse de los resultados científicos de otros colegas para consolidar su carrera profesional.

\subsection{El caso específico de las revistas arbitradas}

Aunque no deseamos propiciar en la imaginación de nadie la figura de un censor, no es esa nuestra intención, se requiere complejizar y hacer mucho más rigurosos los procedimientos de evaluación y criterios de cientificidad que deben aplicársele a los artículos que los editores reciben para la publicación. En nuestro caso, la experiencia nos ha llevado a maximizar las condiciones de exigencias solicitadas a los árbitros, a fin de evitar las tan ominosas situaciones que surgen cuando el déficit de contenido del artículo no solo es manifiesto, sino que se sospecha adulterado. Esta apreciación va más allá de someras observaciones sintáctica, semántica y pragmática del uso del lenguaje, cuando se trata de insistir con toda pertinencia en el valor epistemológico, heurístico y crítico de la investigación con respecto al tema propuesto y los resultados obtenidos.

Es por esta razón que nos hemos ido proponiendo consolidar un comité de árbitros de primer orden, diplomados con 
la titularidad de Doctor, con obra realizada y reconocida nacional o internacionalmente. Árbitros de esta clase sólo reciben artículos previamente evaluados por los miembros del Consejo de Redacción, el Director, el Editor, quienes después de verificar que se cumplen las formalidades de selección, lo remiten a uno de los Asesores nacionales o internacionales, experto en la cuestión, para que dictamine la importancia del tema investigado, dándose curso de esta manera a la escogencia de aquellos árbitros especialista, que efectivamente actúen como auténticos "pares" de los colegas sometido al arbitraje. Las posibilidades de engaño, aunque las consideremos remotas, siempre están presentes. No se quiere decir que con nuestro "modelo" de arbitraje quedemos exentos de la estafa o del fraude intelectual, del perjuicio a los derechos de autor de algún investigador conocido o desconocido. Se trata, sin embargo, de ir concientizando que la producción y difusión del conocimiento por parte de un investigador miembro de una Unidad, Centro, Laboratorio, Instituto, está cada vez más asociada a una ética aplicada y cívica, como lo dice Cortina (1998), que nos hace responsables y co-responsables de los bienes alcanzados por la investigación científica y nos obligan a resolver aquellas faltas de ética que atentan contra el éxito del esfuerzo personal e intelectual, realizado por los investigadores en sus respectivas academias. Al considerar moral la conducta del investigador, se está avalando de igual manera la confianza en la calidad y la originalidad de sus resultados científicos, que al ser compartidos por otras comunidades de investigación (nacionales o internacionales) terminan siendo acreditados por la cultura científica.

En nuestra experiencia editorial nos hemos topado con varios casos en los que la falta de ética de un investigador socava los derechos de autor de otro, sobresaliendo por su inmoralidad manifiesta. Hace unos meses conocimos de un plagio efectuado a un artículo publicado en una revista de circulación internacional. El artículo en cuestión originalmente fue redactado por una estudiante de Maestría como resultado final de un seminario. Después de ser evaluado por los respectivos árbitros especialista en el tema, recibe la aprobación y es publicado a mediados del año 1999. A finales del año 2000 , otro estudiante de esa misma Maestría, profesor universitario, accede a través de un localizador electrónico a una página web en la que se encuentra con la edición de un artículo con similar título al publicado en la revista equis en 1999, que le ha servido de apoyo para su investigación. Cuál es su sorpresa, que después de leer página y media, comienza a percatarse de que está leyendo, palabra por palabra, el artículo cuya autoría, más que demostrada, pertenece a su compañera de Maestría. Pero su sorpresa no se queda allí. Al formular su denuncia ante un miembro del Consejo de Redacción de la revista equis, se descubre que quien suscribe la autoría de la "versión electrónica" del artículo plagiado, resulta ser, para colmo de males, uno de sus asesores internacionales. Aunque insólito, este es un hecho de la realidad.

Las diversas pesquisas que se iniciaron en aquél momento para conocer cómo llegó el artículo plagiado a ser presentado en una página electrónica, no 
arrojó ningún resultado satisfactorio y concreto que pudiera establecer alguna responsabilidad en el caso. La empresa que diseña y administra la página web, manifestó que sólo era responsable de la calidad técnica de la información vaciada. Sin embargo, tuvieron la gentileza de dar a conocer la dirección electrónica de los directores de la revista de la que se suponía estaba tomado el artículo del que se les solicitaba la información. Cuando se revisó el índice de contenido de los números editados en la versión electrónica (que se correspondían con los de la edición en papel), enseguida se detectó que en ninguno aparecía el artículo objeto del plagio. A ese artículo se tenía acceso a través de un "enlace" electrónico determinado por una palabra clave, y ya abierto el archivo del artículo en cuestión, otro "enlace" conecta con otros artículos del autor del plagio, recogidos en la versión electrónica de la revista, de la que él es uno de los principales colaboradores-asesores. Se escribió varias veces al Consejo de Redacción y a la Directora de la revista, a fin de recabar información -que sabemos es confidencial-, sobre lo que a todas luces resultaba ser un plagio -la forma tan astuta de cambiar ligeramente el título, presentar otro resumen en castellano e inglés, elaborar una Introducción de página y media al texto copiado-, con la expresa intención de hacerlo público a través de la página electrónica de una revista especializada sin que formara parte de su contenido temático. Ninguna de las diligencias recibió respuesta. Todavía se gestiona la forma de resolver este caso.

La responsabilidad del Consejo de Redacción, Director y Editor, de la revista agraviada, ante hechos de esta naturale- za, es la de sustanciar debidamente esta denuncia para hacerla llegar a las autoridades respectivas de la comunidad científica, para poder penalizar -con la exclusión y el veto- a este investigador que ha faltado a su ética personal, investigativa y científica. En ninguna de las instancias donde se ha presentado este caso "fuera de serie", se ha podido definir y poner en ejecución una sanción que se corresponda con la gravedad de la falta de ética en la que se ha incurrido.

\section{Conclusiones}

Plagiar los resultados científicos de un investigador, por parte de otro, es un acto de inmoralidad que no tienen ninguna justificación ni debe consentirse bajo ningún pretexto. Precisamente, por tratarse de una comunidad de investigadores, donde se considera que el conocimiento es un bien en común, con un singular impacto dentro del comportamiento de la vida en sociedad, donde la moral privada del investigador está fuertemente asociada a la moral pública en la que se desenvuelve, difícilmente un "investigador" de este tipo puede tener cabida. Quizás por el afán de poder, hacer curriculum, lograr éxitos perentorios, posiciones burocráticas de mando, emolumentos, etc., es que algunos investigadores renuncian sin más, a las normas y valores éticos que orientan a las comunidades científicas a las que pertenecen.

Sin embargo, como ya hemos señalado, al considerarse el derecho de autor como un derecho de fundamentación moral, pero de difícil aceptación legal, porque pertenece al ámbito de la moralidad, el incumplimiento de lo que debe ser 
no deriva un castigo por sanciones externas al sujeto y prefiguradas legalmente. Al respecto señala A. Cortina (1998: 49) que "(...) quien infringe una norma se siente culpable ante su conciencia y la sanción que sufre es más bien el remordimiento".

Los derechos de autor, se basan en una estructura normativa que no procede punitivamente, pero que intenta evitar el pillaje del que es objeto el autor; mucho más, cuando hoy día se disponen de tecnologías -Video, CD-ROM- reproductoras y generadoras de un mercado de intercambio que favorece enormemente la copia, el plagio, el fraude, el lucro sobre productos originales, resultando virtualmente imposible el castigo para estos delitos.

Son muchos los problemas que se intentan resolver por medio de leyes sobre la propiedad intelectual, la de los derechos de autor, así como de las diversas sociedades internacionales que luchan por dar soluciones jurídicas. No sólo en lo que concierne a los problemas más frecuentes causados por el plagio o el lucro, sino aquellos que tienen que ver con las relaciones contractuales entre investigadores y editores (traducciones, ventas en el extranjero, reediciones, etc.), o entre el empresario o el comerciante que busca el patrocinio de los descubrimientos científicos. Todos requieren de una especial atención y consideración.

Es muy amplio el campo de situaciones irregulares que reclaman cada vez más una legislación que de cuenta de los desafueros que se cometen a la sombra de los investigadores honestos, por parte de otros investigadores que no lo son, o personas -incluso empresas- inescrupu- losas. Aunque las leyes no protegen suficientemente todos los derechos que son reconocidos por una moral cívica o por una ética crítica; se trata, sin embargo, como afirma A. Cortina (1998), de producir una norma de valor que sea capaz de responder a la desobediencia ética en que incurren algunas personas -entre ellas algunos investigadores-, al cometer plagio o usura, de la obra auténtica y original de un autor.

Somos conscientes de que se está cuestionando-criticando una realidad en la que es sumamente fácil identificar a la víctima, pero no el victimario que actúa como un espectro. Todos los esfuerzos que se realicen para implementar y disponer de medios que hagan fiable la acreditación de las investigaciones y su respectiva publicación en revistas científicas arbitradas, dependerán del reclamo ético que se le exija al investigador y de esa moral cívica que representa la instancia material donde los valores y normas se cristalizan. Más todavía, porque ella es depositaria de aquellos principios con lo que se regula la conducta cívica, cuyos objetivos se cumplen sólo si se asume con "valor" las responsabilidades que se derivan de las acciones. Debemos canonizar el derecho de autor como una defensa a la libertad creadora del conocimiento.

\section{Bibliografía Citada}

Aranguren, José Luis L (1997). Ética. Biblioteca Nueva, Madrid, España.

Aristóteles (1985). Ética Nicomáquea. Ética Eudema. J.Pallí (trad). Gredos, Madrid.

Cortina, Adela et al (1998). Ética de la empresa. 3를 edición. Trotta, Madrid, España. 
Cortina, Adela (1986). Ética mínima. Tecnos, Madrid.

Cortina Adela (1996a). El quehacer ético. Santillana, España.

Cortina Adela (1996b). "Comités de ética”, en Gauriglia Osvaldo, ed: Cuestiones morales. Enciclopedia Iberoamericana de Filosofía. Vol. 2. Trotta, España.

Delgado Ocando, José Manuel (1998). Una introducción a la ética social descriptiva. Universidad del Zulia, Maracaibo, Venezuela.

Gomez-Muller, Alfredo (1999). Éhique, coexistence et sens. Desclée de Brouwer, Paris.

Habermas, J. (1973). La technique et la science comme "idéologie". Denoël, Paris.
Jaeger, Werner (1968). Paideia: Ios ideales de la cultura griega. F.C.E, México.

Kant, Manuel (1963). Fundamentación de la metafísica de las costumbres. $2^{\circ}$ ed. Espasa Calpes, Madrid.

Congreso de la República (1993). Ley de Derechos de Autor. Gaceta oficial $\mathrm{n}$ ‥ 4.638 (Extraordinaria)/Pía Lara, María (1992). La democracia como proyecto de identidad ética. Anthropos, Barcelona.

Thiebaut, Carlos (1992). "Neoaristótelismos contemporáneos", en Camps Victoria, Gauriglia Osvaldo, y Salmerón Fernando eds (1992). Concepciones de la ética. Enciclopedia Iberoamericana de Filosofía. Vol. 2. Trotta, España. 